exclusivamente a alteraciones en los genes bacterianos que codifican la proteína de unión a la penicilina (PUP) — el blanco natural de estos antibióticos-, de manera que al reducir su afinidad de unión la hace resistente a estos productos.

En este artículo se demuestra la aplicabilidad clínica de la reacción en cadena de la polimerasa (RCP) para detectar tempranamente la resistencia de $S$. pneumoniae a los antibióticos. Para ello se analizaron 153 aislamientos clínicos de esta bacteria aportados por varios hospitales del estado de Porto Alegre, Brasil.

A las muestras se les midió la concentración mínima inhibidora (CMI) de penicilina mediante la prueba de dilución en agar Mueller-Hinton con 5\% de sangre de carnero desfibrinada. Se consideraron susceptibles las cepas con una $\mathrm{CMI} \leq 0,06 \mu \mathrm{g} / \mathrm{mL}$, con resistencia intermedia cuando la CMI estaba entre 0,12 y $1,0 \mu \mathrm{g} / \mathrm{mL}$ y con alta resistencia cuando la $\mathrm{CMI} \geq 2,0 \mu \mathrm{g} / \mathrm{mL}$. Como control se empleó la cepa de S. pneumoniae ATCC 49619. Simultáneamente se realizó un análisis por RCP para detectar el gen lyt $A$ en la cepa aislada y se buscaron amplicones de tallas determinadas $1 \mathrm{a}, 2 \mathrm{~b}$ y $2 \mathrm{x}$ mediante cebadores específicos para los genes de la PUP.

Los resultados demostraron que la resistencia de S. pneumoniae a la penicilina en el sur de Brasil ha aumentado, aunque aún es menor que la observada en otros países. La tasa de cepas resistentes a la penicilina en Porto Alegre fue de 22,8\% (16,3\% con resistencia intermedia y $6,5 \%$ con resistencia alta). Una proporción estadísticamente significativa de las muestras susceptibles a la penicilina no tenían amplicones $(P=0,05), 84 \%$ de las muestras con resistencia intermedia tenían solo uno (por lo general el 2x) y las cepas altamente resistentes tenían los tres amplicones investigados.

La presencia de amplicones $2 x$ de la PUP en la mayoría de las cepas de $S$. pneumoniae con resistencia intermedia a la penicilina indica que estos pueden servir de marcadores de poca resistencia. Sin embargo, no se logró diferenciar las muestras con resistencia intermedia a la penicilina de las que tenían una elevada resistencia mediante la presencia o ausencia de amplicones $2 x$ del gen de la PUP, aunque la presencia simultánea de dos o tres amplicones diferentes se asoció significativamente con la expresión de una alta resistencia.

El diagnóstico molecular de la resistencia a la penicilina se dificulta debido a la asociación de múltiples PUP con el desarrollo de la resistencia. Sin embargo, este estudio demostró que mediante la RCP se pueden detectar tempranamente las cepas de S. pneumoniae con resistencia a antimicrobianos. Esta técnica es rápida y fácil de realizar en laboratorios habilitados para ello. Es necesario diseñar nuevos estudios que permitan determinar cuál de los PUP puede servir mejor de blanco en la RCP, de manera que permita detectar las cepas de neumococos resistentes a antibióticos betalactámicos. (Walker Zettler $\mathrm{E}$, et al. Determination of penicillin resistance in Streptococcus pneumoniae isolates from southern Brazil by PCR. Int J Infect Dis. 2006;10(2):110-5.)

\section{Infección natural del mosquito Lutzomyia neivai con Leishmania spp en Argentina}

La leishmaniasis es una enfermedad causada por parásitos del género Leishmania y transmitida en América por la picadura de mosquitos del género Lutzomyia (Diptera: Psychodidae: Phlebotominae). En el norte de Argentina se han detectado casos y epidemias de leishmaniasis cutánea americana (LCA) desde 1916. Entre 1991 y 1997 se han documentado 203 casos nuevos de esta enfermedad en la provincia argentina de Tucumán.

La especie Lutzomyia neivai se considera el principal vector de la LCA en Argentina; sin embargo, aún no se sabe si este mosquito se infecta de manera natural con el parásito. Conocer la tasa de infección natural de este vector e identificar las especies circulantes del parásito constituyen elementos de gran importancia para diseñar las medidas de vigilancia vectorial y epidemiológica.

El objetivo de este trabajo fue detectar la infección natural del mosquito vector con especies de leishmania en un área con LCA endémica del norte de Argentina y determinar el subgénero del parásito mediante técnicas de biología molecular. Además, se buscó confirmar que la especie $L u$. neivai puede transmitir la enfermedad en esta área, como se desprende de su distribución y abundancia estacional coincidente con el patrón epidemiológico de la LCA en esta zona.

Se recolectaron mosquitos en seis localidades de las provincias argentinas de Tucumán (cinco localidades) y Salta (una localidad), ambas en la zona noroccidental del país, entre noviembre de 1999 y enero de 2003. Después de la identificación morfológica, el ADN de 410 hembras de Lu. neivai (310 de Tucumán y 100 de Salta) se extrajo y se amplificó mediante la reacción en cadena de la polimerasa (RCP) con cebadores específicos de Leishmania spp, y se determinaron los subgéneros L. (Viannia) y L. (Leishmania) mediante técnicas de hibridación de ADN con sondas obtenidas de cepas de L. (V.) braziliensis y L. (L.) amazonensis.

De los 2749 insectos recolectados en Tucumán, 96,5\% pertenecían a la especie $L u$. neivai, 3,2\% a Lu. migonei y 0,3\% a Lu. shannoni. En Salta, la especie predominante fue también $L u$. neivai (94\%). 
Según los resultados del análisis molecular de las muestras, se encontró ADN de L. (Viannia) en 9,1\% de las muestras de mosquitos Lu. neivai estudiados. La proporción de mosquitos infectados fue de $0,9 \%$ y dichos mosquitos se capturaron en zonas de bosques primarios y secundarios, así como en áreas peridomésticas de la región de mayor incidencia de LCA en el país. En estudios previos no se encontraron parásitos en ninguno de los 3341 mosquitos hembras de la especie $L u$. neivai, como tampoco en los 94 de la especie $L u$. migonei examinados microscópicamente por otros autores, a pesar de que se recolectaron en un área con leishmaniasis hiperendémica.

Este es el primer informe publicado sobre la infección natural de mosquitos en Argentina. La aplicación de la técnica de RCP-hibridación de ácidos nucleicos permitió determinar que el parásito que circula en el noroeste argentino y que posiblemente es el agente causal de la leishmaniasis en esa región pertenece al subgénero Leishmania (Viannia). Estos resultados contribuyeron también a establecer la participación de Lu. neivai y Lu. migonei en la transmisión de esta infección. (Córdoba-Lanús E, et al. Natural infection of Lutzomyia neivai with Leishmania spp. in northwestern Argentina. Acta Trop. 2006;98(1):1-5.)

\section{Relación entre la situación socioeconómica y la obesidad en países de diferente nivel de desarrollo}

El estadio de desarrollo social y económico puede influir en la relación entre la situación socioeconómica (SSE) y la obesidad y en la forma en que esta se manifiesta en los diferentes países. Recientemente Fezeu y colaboradores (Fezeu L, Minkoulou E, Balkau B, et al. Association between socio-economic status and adiposity in urban Cameroon. Int J Epidemiol. 2006;35:105-11) examinaron la relación entre la SSE y la adiposidad en un estudio transversal de base poblacional realizado en una zona urbana de Camerún. Los autores encontraron una relación directa entre la SSE y la obesidad, a diferencia de lo encontrado por otros autores en países desarrollados. Por la importancia del tema, en este artículo se discute la forma de interpretar esos resultados a la luz del creciente e importante problema de la obesidad.

Un aspecto metodológico fundamental en cualquier estudio sobre SSE y obesidad es la conveniencia de ajustar algunos factores. Sin embargo, el consumo y el gasto energético realmente funcionan como mediadores, por lo que no se deben ajustar en este tipo de estudios. La actividad física está estrechamente relacionada con el nivel de gasto energé- tico y tanto el tiempo libre como el tiempo dedicado a alguna actividad física influyen en ello. Por lo tanto, el tratamiento cuidadoso del tiempo dedicado a actividades físicas y del tiempo libre es crucial para lograr resultados sin sesgos en este tipo de estudio.

En los países desarrollados de Europa y de América se ha encontrado - con raras excepcionesuna asociación inversa entre la SSE y la obesidad, independientemente de la forma de evaluar la SSE, ya sea en función del nivel educacional, los ingresos o la ocupación laboral. No obstante, esa asociación ha resultado directa en la mayoría de los países en estadios más tempranos de desarrollo.

Esa asociación directa encontrada entre la SSE y la obesidad en estudios transversales como el realizado en Camerún no permite establecer una relación causal que implique que la obesidad tienda a reducir el SSE o que el aumento de la obesidad y la disminución de la SSE puedan tener causas comunes. Por el contrario, esa asociación directa entre la SSE y la obesidad calculada a partir del confort del hogar y la adiposidad parece apoyar la hipótesis de que la transición en el desarrollo socioeconómico de una comunidad va acompañada de cambios en el estilo de vida (patrones alimentario y de actividad física, entre otros) que pueden explicar esa asociación.

Esa transición en los hábitos alimentarios y en la práctica de actividad física conduce a una mayor prevalencia temporal de la obesidad. Estudios recientes informan que en los primeros estadios de desarrollo económico y social de cualquier país, la carga de la obesidad pasa rápidamente a los segmentos de la población de menos recursos. Esto puede explicarse porque desaparecen poco a poco la escasez de alimentos y el gran gasto energético de los más pobres, mientras que las personas con mejor SSE adquieren alimentos más apropiados y conservan valores culturales que llevan a presumir de un cuerpo esbelto como símbolo de pertenecer a un segmento privilegiado de la población. En otras palabras, con el desarrollo socioeconómico desaparecen los factores que protegen a los pobres contra la obesidad, mientras que se mantienen y fortalecen los que protegen a las clases de mejor SSE.

De todo lo expresado se concluye que la asociación directa entre la SSE y la obesidad observada en los países en desarrollo no debe interpretarse como un indicador de que los segmentos más desfavorecidos gozan de mejor salud. En los países que comienzan a experimentar un acelerado desarrollo socioeconómico se deben tomar medidas para evitar la obesidad y los trastornos asociados con ella desde mucho antes de que comiencen a incrementarse las tasas de obesidad en la población. (Song YM. Commentary: varying relation of socioeconomic status with obesity between countries at diffe- 